\title{
The Use of Arnica TABlets By Runners IN THE 90 KILOMETER COMRADES MARATHON
}

\author{
ABSTRACT: Background: Arnica is a homeopathic remedy which is \\ sometimes used before and after long distance running in the belief that \\ it reduces delayed onset muscle soreness (DOMS). However, the specific \\ details of its use among athletes is not known. Therefore the aim of \\ this study was to determine the usage patterns of Arnica tablets amongst \\ participants in the 1999 ninety-kilometer Comrades ultra-marathon road \\ race in South Africa. \\ Methods: Every third runner registering for the race in Pietermaritzburg \\ in the three-day (25 hour) pre-race registration period was approached \\ and asked to complete a questionnaire on their use of Arnica tablets \\ $(n=785 ;$ males $=85 \%$ and females $=15 \%)$. \\ CYNTHIA M BAUER', \\ BSc Physio, BSc Med, B.A \\ MICHAEL I LAMBERT ${ }^{2}$, PhD \\ LINDSAY M WEIGHT ${ }^{3}$, PhD

\footnotetext{
'Faculty of Health Sciences, Department of Physiotherapy, University of Cape Town.

2 MRC/UCT Research Unit for Exercise Science and Department of Human Biology, Faculty of Health Science, University of Cape Town.

${ }^{3}$ Department of Human Biology, Faculty of Health Science, University of Cape Town.
} \\ Sports Medicine, Sports Science Institute of South Africa,
}

Results: Ten percent of the total study population who agreed to participate in the study $(n=730)$ had used Arnica tablets in the previous six months. The average reported dose by these athletes was seven tablets per day. The most common reason for using Arnica tablets was to decrease pain or stiffness after a race or training run. Only a small group (22\%) rated the efficacy of Arnica tablets as "totally effective", suggesting that a large number of users of Arnica did not rate the efficacy highly. There was a poor relationship between the perceived efficacy after ingesting Arnica tablets and the reported dosage $(r=0.28)$. The majority of the respondents (63\%) believed that Arnica tablets contained anti-inflammatory agents.

Conclusions: While 10\% of the runners used Arnica, only one fifth of these runners rated the treatment as completely effective for the prevention of DOMS. Therefore education on the advantages and disadvantages of using these tablets has become important.

\section{KEY WORDS: ARNICA TABLETS, LONG DISTANCE RUNNING, MUSCLE SORENESS, HOMEOPATHY}

\section{INTRODUCTION}

There is growing anecdotal evidence of the use of homeopathy amongst sports' participants, in particular long distance runners and other endurance athletes. Arnica tablets are frequently used as a prophylactic agent both before and after long distance running in the belief that the treatment reduces delayed onset muscle soreness (DOMS). However, although homeopaths often use Arnica tablets for the treatment of soft tissue

\section{CORRESPONDENCE TO:}

Associate Professor Mike Lambert MRC/UCT Research Unit for Exercise Science and Sports Medicine, P.O. Box 115,

Newlands 7925

South Africa

Tel: (021) 650-4558

Fax: (021) 686-7530

Email: mlambert@sports.uct.ac.za trauma, there is equivocal evidence of its efficacy [Lokken et al, 1995; Jawara et al, 1997]. One viewpoint is that homeopathy's long history and continued successful use worldwide convincingly demonstrates its efficacy in the treatment of injuries and wounds [Lokken et al, 1995]. An alternative viewpoint is that the lack of convincing scientific evidence is a major reason why homeopathy is generally not accepted by the medical community [Lockie, 1998]. Despite the discrepancy between the viewpoints of the practitioners of homeopathy and medicine, the use of homeopathic remedies, among them Arnica tablets, is still widespread. No studies could be found to establish the details on the use of Arnica tablets.

Therefore the main aim of this study was to determine the prevalence of usage of Arnica tablets in a group of ultra-endurance athletes. A secondary aim was to determine the perceptions of its efficacy, constituents, dosage and the most commonly used commercial brand in this group of runners. This may serve to determine whether the reasons for using Arnica are matched by their purported effects.

\section{METHODS}

Ethical approval for the study was obtained from the Ethics and Research Committee of the Faculty of Health Sciences, University of Cape. The questionnaire was evaluated in a pilot study administered to 63 marathon runners who were members of a Johannesburg running club, whereafter poorly constructed and/or ambiguous questions were identified and modified. Registration for the 1999 Comrades marathon took place at two venues during the three days before the race. An attempt was made to target every third runner registering in Pietermaritzburg. These runners were approached and 
asked to complete the questionnaire. The name, Comrades marathon 1999 race number and gender of those runners who declined to complete the questionnaire were recorded where possible.

The sample group was divided into the following subgroups: runners who agreed to answer the questionnaire versus those runners who declined, male versus female, and runners who had previously heard of Arnica tablets versus runners who had not. Those runners who reported having previously used Arnica tablets were further analysed as a subgroup. They were required to answer questions on their perceptions on the efficacy of Arnica tablets, the constituents of the tablets and their dosage used. The efficacy of Arnica was assessed by asking the subjects to evaluate their efficacy on a scale of " 0 " (absolutely no) to "7" (absolutely yes).

Data are expressed as absolute values, percentages and means (standard deviation [SD]). The Chi squared statistic was used to determine significant differences between groups for the prevalence data. An independent t-test was used to determine differences between groups for all parametric variables. A Spearman's correlation coefficient was calculated to determine the relationship between the dosage of Arnica tablets and the perceived efficacy of the treatment. Statistical significance was accepted as $\mathrm{P}<0.05$.

\section{RESULTS}

The general characteristics of the total study population and sub-populations are shown in Table 1. The total respondent population was $\mathbf{n}=730$ (male $85 \%$, female $15 \%$ ). Twenty-nine percent of this population had heard of Arnica tablets previously (males $22 \%$, females $7 \%$ ). This represents $26 \%$ of the male population and $50 \%$ of the total female population when the data were stratified for gender.

Of the runners who had heard of Arnica tablets, the most common brand was Weleda (Pharma Natura) $(71 \%)$, Bioforce $(7 \%)$, and "other" (4\%). The respondents were allowed to indicate more than one brand. Twenty four percent of the subjects were not able to identify a specific brand. Of those

Table 1: Characteristics of the study population.

\begin{tabular}{|l|c|c|c|}
\hline & Respondents & Declined $^{*}$ & Total \\
\hline Males & $623(85 \%)$ & $54(98 \%)$ & $677(86 \%)$ \\
\hline Females & $107(15 \%)$ & $1(2 \%)$ & $108(14 \%)$ \\
\hline Total & 730 & 55 & 785 \\
\hline
\end{tabular}

${ }^{*}$ these runners declined to answer the questionnaire and participate in the study.

Table 2: Prevalence of Arnica tablet users in the study population $(n=730)$.

\begin{tabular}{|c|c|c|c|}
\hline & Users & Non-users & Total \\
\hline All respondents & $72(10 \%)$ & $658(90 \%)$ & 730 \\
\hline Genders: Males & $22(31 \%)$ & & \\
\hline Females & $50(69 \%)^{*}$ & & \\
\hline
\end{tabular}

*Significantly higher in female compared with male $(p<0.05)$.

Table 3: The source from whom the respondents $(n=72)$ heard about Arnica.

\begin{tabular}{|l|c|c|}
\hline Source of advice & Number & $\%$ \\
\hline Other runners & 20 & 28 \\
\hline Physiotherapists & 8 & 11 \\
\hline Homeopaths & 8 & 8 \\
\hline Pharmacists & 6 & 7 \\
\hline Medical doctors & 5 & 28 \\
\hline Other & 20 & $6)$ \\
\hline (Wife & 4 & (1) \\
\hline
\end{tabular}

(Respondents could indicate $>$ than 1 source. Not all respondents answered this question)

Table 4: Reported reasons for using Arnica $(n=72)$.

\begin{tabular}{|l|c|}
\hline Reported reason & $\%$ \\
\hline Used after a race/run to minimize pain/stiffness & $61 \%$ \\
\hline Used before a race/run to minimize pain/stiffness & $41 \%$ \\
\hline To improve the ability to train harder & $4 \%$ \\
\hline Other purposes related to running & $11 \%$ \\
\hline Purposes unrelated to running & $36 \%$ \\
\hline "Sore muscles" not related to running & $8 \%$ \\
\hline
\end{tabular}

subjects who had heard of Arnica tablets, 34\% $(\mathbf{n}=72)$ had used them in the previous six-month period. This represents $10 \%$ of the total sample of runners. These data are summarized in Table 2. There was a significantly higher prevalence of use among female $(69 \%)$ compared with male $(31 \%)$ $[\mathrm{P}<0.05]$ respondents.

Those runners who used Arnica tablets previously were advised from a variety of sources (Table 3). Respondents frequently indicated that they were advised from more than one source. The common sources in this study population were other runners (28\%), physiotherapists $(11 \%)$, homeopaths $(11 \%)$, pharmacists $(8 \%)$ and doctors $(7 \%)$. Twenty eight percent had been advised by another source, of which "wife" was the most frequent $(6 \%)$ in this sub-group.

The main reasons for which Arnica tablets were used by the respondents are depicted in Table 4. Respondents could indicate more than one reason for 
Table 5: Data of the runners who declined to fill in the questionnaire $136 \%$ of the total non-responders) compared to the responders. The sample size $(n)$ varies depending on the numbers of responses to the questions.

\begin{tabular}{|l|c|c|c|c|}
\hline & \multicolumn{2}{|c|}{ Non-responders } & \multicolumn{2}{c|}{ Responders } \\
\hline Variable & $\mathrm{n}$ & Mean \pm SD & $\mathrm{n}$ & Mean \pm SD \\
\hline Age (years) & $(20)$ & $38 \pm 9$ & $(730)$ & $38 \pm 9$ \\
\hline Comrades 1999 time (min) & $(19)$ & $544 \pm 77$ & $(568)$ & $576 \pm 69$ \\
\hline Comrades PB (min) & $(20)$ & $528 \pm 79$ & $(645)$ & $542 \pm 76$ \\
\hline Number of medals & $(20)$ & $5 \pm 4$ & $(646)$ & $6 \pm 5$ \\
\hline
\end{tabular}

( $\mathrm{PB}=$ personal best time)

using Arnica tablets. The most frequently reported reasons for using Arnica tablets were to minimize pain and stiffness after a run/race $(61 \%)$ or before a run/race to reduce pain/stiffness $(41 \%)$. Four percent of the respondents used Arnica tablets to improve their ability to train harder while 11\% used Arnica tablets for "other" reasons. Arnica tablets were also used for conditions unrelated to running $(36 \%)$ of which $8 \%$ listed "sore muscles" as the reason.

Only $22 \%$ of those runners who had used Arnica tablets previously regarded their effects to be completely effective while $1 \%$ found them to be totally ineffective. Thirty-three $\%$ of the subjects were ambivalent when asked about the efficacy.

The runners who had used Arnica tablets took an average of seven tablets per day for an average of seven days. Nineteen respondents $(26 \%)$ who used Arnica tablets ingested more than seven tablets a day and scored their efficacy as $80 \%$. Forty-one subjects $(57 \%)$ took less than seven tablets a day and scored their efficacy as $71 \%$. Twelve users ( $17 \%$ ) did not respond to this question. The relationship between the dosage and perceived efficacy of Arnica tablets was poor $(r=0.28)$.

Runners believed Arnica tablets contain various substances. The commonest perceptions were that Arnica tablets had anti-inflammatory properties $(63 \%)$, contained 'anti-swelling' agents (38\%) and pain relievers (17\%). Eleven percent responded to "other" as a constituent and $19 \%$ did not know the answer to this question. No runner listed "stimulants" as a constituent of Arnica.

Fifty-five of the runners $(7 \%)$ of the total study population who were approached, declined to fill in the questionnaire. Data which were obtained for $36 \%$ of these "non-responders" were their age, 1999 Comrades marathon time, Personal Best (PB) Comrades marathon time and total number of Comrades marathons completed (Table 5). There was no significant difference in these parameters between those who answered the questionnaire and those who declined to answer the questionnaire (Table 5).

\section{DISCUSSION}

The main aim of this study was to determine the prevalence of usage of Arnica tablets in a group of ultra-endurance athletes using a self-reported questionnaire. Data obtained from self-reported questionnaires are open to criticism because the responses are difficult to validate. For this reason the questionnaire was tested in a pilot study and any questions which were ambiguous or misinterpreted were adjusted accordingly. The targeted runners completed the questionnaires in a controlled environment and the method of gathering data was believed to be valid. Furthermore, the sampling procedure was designed to select subjects in a systematic way to avoid bias. The targeted runners who declined to answer the questionnaire had similar population demographics compared to those runners who answered the questionnaire. Therefore it is reasonable to assume that the results of the runners who responded to the questionnaire in this study are an accurate representation of the study population (Comrades marathon runners).

The main finding of the study was that ten percent of the total study population had used Arnica tablets in the previous six months and twenty-nine percent of the total respondent study population had heard of Arnica tablets. Furthermore, women were more likely to have been aware of Arnica or to have used Arnica tablets than men. Another finding of the study was that only $22 \%$ of the subjects who had used Arnica tablets previously rated their effects as completely effective. This finding can be interpreted in two ways. Either the treatment is ineffective in most cases, or alternatively the Arnica is not being used is the correct dosages or potencies. A fundamental principle of homeopathy is that one remedy does not necessarily help every patient with a similar complaint. The therapeutic objective of homeopathy is to treat the individual and the whole body and not just the specific condition [Koehler, 1986]. Classically, homeopathy is based on individualised treatment with drugs and doses selected according to the signs, symptoms and individual temperament of the patient - factors which are not accommodated in the standard research protocols of science and medicine [Weight, 2000]. This principle poses a problem for conducting a scientific, double-blind, placebo controlled study, making the evaluation of the efficacy of Arnica tablets difficult. As a result there is no consensus on the efficacy of Arnica in the literature. For example Tveitan et al [1991] assessed the affect of arnica montana D30 tablets on runners competing in the 1990 Oslo Marathon. Those runners ingesting Arnica tablets experienced less muscle stiffness and had less muscle damage after the race as shown by lower plasma creatine activity. However, there was no difference in the duration of soreness between this group and the group who took the placebo. It was concluded from this study that Arnica tablets did not reduce long term muscle damage but did reduce acute muscle soreness. In another study, Vickers et al [1998] conducted a randomized, double-blind, placebo controlled trial on 519 long-distance runners to determine whether treatment with Arnica 30X tablets decreased delayedonset muscle soreness more effectively than placebo following long-distance running. Results obtained from 400 runners led them to conclude that Arnica 
tablets were ineffective in reducing muscle soreness based on the fact that the runners' perception of post-exercise pain was not decreased in the control group. Therefore, based on these data there is no justification to recommend Arnica tablets before and after long distance racing.

It is interesting to note that despite the lack of clinical trial data, and the low $(22 \%)$ perception of efficacy in our study, that $10 \%$ of the runners still chose to use Arnica. This can perhaps be attributed to the recent surge in consumer interest and acceptance of alternative medicine, which has resulted in a tendency to self-medicate without due regard or knowledge of the advantages and disadvantages of Arnica tablets.

In conclusion, $10 \%$ of the runners in a major event in South Africa make use of Arnica. Only one fifth of these runners rate the treatment as completely effective for the prevention of DOMS, and therefore education on the advantages and disadvantages of using these tablets has become important. Ultraendurance athletes need further education on the use of Arnica tablets as their expectations for using Arnica tablets are not matched by the purported affects of the homeopathic agent. Future research should determine whether the consumption of Arnica should be reduced because of the poor efficacy or whether the poor efficacy is a result of incorrect usage patterns.

\section{ACKNOWLEDGEMENTS}

The Medical Research Council and the Nellie Atkinson and Harry Crossley Research Funds of the University of ,Cape Town and Weleda (Pharma Natura) supported this study. Gill Cohen of the Comrades Marathon Association is thanked for her support.

\section{REFERENCES}

Jawara N, Lewith G T, Vickers A J, Mullee M A, Smith C 1997 Homeopathic arnica and Rhus toxidendron for delayed onset muscle soreness. British Homeopathic Journal 86:10-15

Koehler G 1989 The Handbook of Homeopathy: Its Principles and Practice. Healing Art Press, Vermont
Lockie A 1998 The family guide to homeopathy, 2nd edn. Hamish Hamilton, London

Lokken P, Straumshein P A, Tveitan D, Skelbreds P, Borchgrevink C F 1995 Effect of homeopathy on pain and other events after acute trauma: placebo controlled trial with bilateral oral surgery. British Medical Journal 310:1439-1442

Tveitan D, Bruseth S, Borchgrevink C F, Lohne K 1991 Effect of Amica D30 during hard physical exertion. Adouble-blind randomized trial during the Oslo Mararthon. Tidsskr Nor Laegeforen 111:3630-3631

Vickers A J, Fisher P, Smith C, Wyllie S E, Ross R 1998 Homeopathic Arnica 30X is ineffective for muscle soreness after long distance running: a randomised, double-blind placebo-controlled trial. Clinical Journal of Pain 14:227-231

Weight L 2000 Evidence for arnica? Runners World (SA) January: 9-10 